HEALTH PSYCHOLOGY REPORT · VOLUME 6(1), 2018 ORIGINAL ARTICLE
Sunna Gestsdottir

$1 \cdot \mathrm{A}, \mathrm{B}, \mathrm{C}, \mathrm{D}, \mathrm{E}, \mathrm{F}$

Erla Svansdottir

$1 \cdot A, D, E, F$

Hedinn Sigurdsson

$2 \cdot \mathrm{C}, \mathrm{D}, \mathrm{E}$

Arsaell Arnarsson

$3 \cdot \mathrm{B}, \mathrm{D}, \mathrm{E}, \mathrm{F}$
Yngvar Ommundsen

$4 \cdot \mathrm{A}, \mathrm{D}, \mathrm{E}$

Sigurbjorn

Arngrimsson

$1 \cdot \mathrm{A}, \mathrm{B}, \mathrm{E}$

Thorarinn Sveinsson

$1 \cdot \mathrm{A}, \mathrm{B}, \mathrm{C}, \mathrm{D}$

Erlingur fohannsson

$1,5 \cdot A, B, E, F, G$

\title{
Different factors associate with body image in adolescence than in emerging adulthood: A gender comparison in a follow-up study
}

\section{BACKGROUND}

Body image dissatisfaction has been linked with a range of adverse psychosocial outcomes in both genders and has become an important public health issue. Across all ages, women have reported being more dissatisfied with their bodies than men. The aim of the current study was to examine if fitness and physical activity associate with body image satisfaction differently across gender and age, measured in the same participants.

\section{PARTICIPANTS AND PROCEDURE}

Participants were measured initially at age 15 years $(N=385)$ and again at age 23 years $(N=201)$. Structural equation modelling was used to examine the association between body image satisfaction, fitness, and physical activity. Covariates included skinfold thickness, body mass index, socioeconomic status, anxiety, and depression.

\section{RESULTS}

Fitness and physical activity declined during the study period, body mass index increased, but no changes were found in body image satisfaction, depression, anxiety, or skinfold thickness. For women at ages 15 and 23 years, self-reported fitness and depression were found to be related to body image satisfaction, including body mass index at the age of 23 years. For 15-year-old men, skinfold thickness and aerobic fitness related to body image satisfaction, whereas skinfold thickness, depression, body mass index, and self-reported fitness did so at age 23 years.

\section{CONCLUSIONS}

Results suggest that different approaches are needed across gender to improve body image in adolescence whereas more similar ones can be used in emerging adulthood.

KEY WORDS

body image; fitness; physical activity; exercise; youth

ORGANISATION - 1: University of Iceland, Reykjavík, Iceland · 2: Glaesibaer Primary Health Care Centre, Reykjavík, Iceland · 3: University of Akureyri, Akureyri, Iceland · 4: Norwegian School of Sport Sciences, Oslo, Norway ·

5: Western University of Applied Science, Bergen, Norway

aUthors' Contributions - A: Study design - B: Data collection - C: Statistical analysis - D: Data interpretation . E: Manuscript preparation · F: Literature search · G: Funds collection

CORRESPONDING AUthor - Sunna Gestsdottir, Ph.D., University of Iceland, Stakkahlíð, 105 Reykjavik, Iceland, e-mail: gsg31@hi.is

to Cite this ARTiCle - Gestsdottir, S., Svansdottir, E., Sigurdsson, H., Arnarsson, A., Ommundsen, Y., Arngrimsson, S., Sveinsson, T., \& Johannsson, E. (2018). Different factors associate with body image in adolescence than in emerging adulthood: A gender comparison in a follow-up study. Health Psychology Report, 6(1), 81-93. doi: https://doi. org/10.5114/hpr.2018.71201 


\section{BACKGROUND}

All individuals have a certain perception of their own body, called body image. The view on body image is two dimensional: attitudinal and perceptual (Soponaru, Bojian, \& Lorga, 2016). The attitudinal dimension is a subjective evaluation, positive or negative, of one's body, based on the social desirability of physicality (Haugen, Säfvenbom, \& Ommundsen, 2011; Strice $\&$ Whitenton, 2002). The perceptual dimension is the accuracy of individuals estimations of their body image (Soponaru, Bojian, \& Lorga, 2016). Negative evaluation of the body, termed body image dissatisfaction has been linked to a range of adverse psychosocial outcomes, including depression, anxiety, low self-esteem, eating disorders, and obesity (Cruz-Saez, Pascual, Salaberria, \& Echeburua, 2015; Darby, Hay, Mond, Rodgers, \& Owen, 2007; Dooley, Fitzgerald, \& Giollabhui, 2015; Stice, 2002; Wiederman \& Pryor, 2000). The emergence of body image dissatisfaction commonly follows the pubertal changes in adolescence when both genders become more aware of their bodies, and start a comparison to others (Markey, 2010). Importantly, findings from Bucchianeri, Arikian, Hannan, Eisenberg, and Neumark-Sztainer (2013) suggest that body image dissatisfaction is more than a 'phase' during adolescence, as it continues into emerging adulthood. Individuals of all body sizes have been found to be dissatisfied with their bodies, although higher body mass index (BMI) has been related to higher levels of body image dissatisfaction in non-clinical samples (Sarwer, Thompson, \& Cash, 2005). The Western thin beauty ideal is also a risk factor for body dissatisfaction by ways of portraying women as slim, tall, and young (Levine \& Chapman, 2012), whereas an extremely lean and muscular body symbolises the perfect body for men (Cafri \& Thompson, 2004). The comparison to cultural values, e.g. Western beauty ideals, is in line with Vygotsky's sociocultural theory (1978), which presents that individuals who perceive themselves and who are being perceived by others are influenced by cultural values.

Body image evaluations have a vital significance for the psychological functioning and social relationships of individuals; body image is thus considered a major contributor to mental well-being (Holsen, Jones, \& Birkeland, 2012). This association may, however, have different implications across gender. That is, gender differences in body image satisfaction are well-established for all age groups with the prevalence of body image dissatisfaction being higher among women than men (Lawler \& Nixon, 2011; Meland, Haugland, \& Breidablik, 2007). Findings among Icelandic youths (Gestsdottir et al., 2015) mirror these results, where men were found to be more satisfied with their bodies compared with women of the same age, both during adolescence and emerg- ing adulthood. Studies have shown that body image dissatisfaction in women is more strongly correlated with clinical eating disorders targeting weight loss. Conversely, it has been associated with food supplement abuse and the use of anabolic steroids in men aiming to gain muscle mass (Mellor, Fuller-Tyszkiewicz, McCabe, \& Ricciardelli, 2010; Smolak, 2004). However, little is known if different factors associate with body image satisfaction among men and women and at different time points in their lives.

\section{EXERCISE AND BODY IMAGE}

Participating in physical activity (PA) is known to be beneficial for the mental well-being of individuals, including body image satisfaction. Gaspar, Amaral, Oliveira, and Borges (2011) found in their cross-sectional study that higher levels of PA in adolescents had a positive effect on body image satisfaction, independent of BMI or gender. These findings are in line with the meta-analytic review of Hausenblas and Fallon from 2006, which concluded that exercise is associated with less body image dissatisfaction across all ages (adolescents, university students, adults, and the elderly). Their review also covered intervention studies, in which exercising subjects reported more body image satisfaction than the non-exercising controls.

While there is evidence indicating that exercise is beneficial for mental well-being and their interrelationship with body image satisfaction, the underlying mechanism for this relationship is less clear. Ortega, Ruiz, Castillo, and Sjostrom (2008) proposed, after their review on the association of fitness with several health outcomes in young people, two possible explanations for the positive effect of fitness on mental well-being. Firstly, improvement in fitness is usually accompanied with a visible increase in lean mass and a decrease in fat mass, leading to more body image satisfaction. Secondly, they suggested the possibility that improved fitness has a direct effect on neurochemicals, like serotonin or endorphins in the brain, that are important for mood elevation. Persons with a more favourable body image are perhaps more likely to take better care of their bodies by being more comfortable about exercising in public. Body image satisfaction may, therefore, be seen as a key factor underlying the development of both mental and physical health for both genders (Darby et al., 2007; Stice, 2002; Wiederman \& Pryor, 2000).

\section{CURRENT STUDY}

As Bucchianeri et al. (2013) have pointed out, body image dissatisfaction is not merely a feeling that occurs only during adolescence but continues to influence the mental well-being and self-esteem of indi- 
viduals long into emerging adulthood (Darby et al., 2007; Rosenberg, Schooler, Schoenbach, \& Rosenberg, 1995). Therefore, it is of value to study which factors influence body image at different life stages, and the aim of the current study was to examine the relationship between fitness and PA to body image satisfaction among men and women during their adolescence and again during emerging adulthood. The reason for we use both objective and a subjective measure of fitness is that very few studies have concomitantly examined the relationship of both types of measures to body image satisfaction. It is also well established that women are more dissatisfied with their body than men are, which might indicate that they view themselves in worse fitness state than men do. We also use two types of measure for body composition: BMI and skinfold thickness. As BMI has been widely used it enables comparison to other studies. However, it has been criticised that BMI does not differentiate between lean body mass and body fat (e.g. Böhm \& Heitmann, 2013) and is, therefore, a crude surrogate for obesity. A measure of skinfold thickness is a more accurate measure of obesity and might give a better idea of the masculine sociocultural body ideal, which has been found to be important to men (e.g. Jones \& Crawford, 2005). Moreover, as body image dissatisfaction seems to affect the genders differently (Bearman, Presnell, Martinez, \& Stice, 2006; Jones \& Crawford, 2005; McCabe \& Ricciardelli, 2003), it may be that different factors contribute to a healthy body image in men and women, and in turn that those factors change over time. In the Icelandic setting, two recent follow-up studies from the same participants, giving an insight into these factors, may interrelate. Firstly, the study of Gestsdottir et al. (2016) showed that aerobic fitness in adolescence was a stronger predictor of body image satisfaction in emerging adulthood than self-reported fitness or PA. Secondly, the study of Gestsdottir et al. (2015) showed that the mental well-being of men remained stable from adolescence to emerging adulthood, contrary to women, who improved their mental well-being, with increased self-esteem and life satisfaction, during the same period. Among emerging adults, men were less satisfied with life than same age women, and a larger proportion of them were classified as having low self-esteem.

No study, to our knowledge, has analysed if body image satisfaction associates with the same biopsychosocial factors in adolescence (when individuals are more likely to be preoccupied by their physical appearance after puberty) and emerging adulthood (when individuals should be more used to their physical appearance). The research question was: Do different factors relate to body image satisfaction at different life stages? We hypothesised that different factors associate with body image satisfaction in men and women at different life stages.

\section{PARTICIPANTS AND PROCEDURE}

Baseline measurements were taken in a randomly selected sample (see Gestsdottir et al., 2016 for how it was selected) of 15-year-olds from a nationally representative cohort in Iceland, and follow-up measures of the same group were conducted eight years later when the participants had reached 23 years of age. Both the first and second measurement phases were carried out between August and January. All study instruments were in Icelandic. The baseline study sample consisted of 385 adolescents (aged 15 years), 190 girls and 195 boys. At follow-up, a total of 201 participants (aged 23 years), 92 young women and 109 young men, were recruited for the second measurement. Total dropout from baseline to follow-up was $48 \%$, of which $19 \%$ refused to participate again, $15 \%$ lived abroad, and $14 \%$ were not located. No significant differences were found in body image scores, PA, aerobic fitness, self-reported fitness, or BMI at baseline between dropouts and participants, but dropouts had higher skinfold thicknesses than non-dropouts. The total number of participants who finished each measurement at baseline and follow-up can be viewed in Table 1 .

Approximately $90 \%$ of the estimated 290,000 inhabitants of Iceland in 2003 and about $85 \%$ of the estimated 320,000 inhabitants in 2011 were of Norse and Celtic origin (Statistics Iceland, n.d.-a). Furthermore,

Table 1

Number of participants finishing each measurement at baseline and follow-up

\begin{tabular}{lcccccc}
\hline Part of study & \multicolumn{3}{c}{ Adolescents } & \multicolumn{3}{c}{ Young adults } \\
\cline { 2 - 7 } & Women & Men & Total & Women & Men & Total \\
\hline Questionnaire & 190 & 195 & 385 & 92 & 109 & 201 \\
Body mass index & 215 & 228 & 443 & 92 & 109 & 201 \\
Fitness & 114 & 122 & 236 & 79 & 102 & 186 \\
Skinfold thickness & 215 & 228 & 443 & 92 & 109 & 201 \\
Physical activity & 81 & 92 & 173 & 69 & 79 & 148 \\
\hline
\end{tabular}


Sunna Gestsdottir,

Erla Svansdottir,

Hedinn

Sigurdsson,

Arsaell Arnarsson,

Yngvar

Ommundsen, Sigurbjorn

Arngrimsson,

Thorarinn

Sveinsson,

Erlingur

Johannsson
$87 \%$ and $77 \%$ of the population belonged to the Lutheran State Church in 2003 and 2011, respectively (Statistics Iceland, n.d.-b). Due to this homogeneity, variables such as race, ethnicity, and religion were not included in the analyses of this study. Socioeconomic status (SES) was not adjusted for at the baseline, due to missing data on the SES measure (which was based on a questionnaire that parents filled out). Analyses at follow-up were adjusted for SES, based on parental education status as reported by participants. About the same proportion of women and men were unemployed at the follow-up, at 4\% (Gestsdottir et al., 2015).

The research project was approved by the Icelandic Bioethics Committee and the Icelandic Data Protection Authority according to the Icelandic Act on Processing of Personal Data. Written informed consent was obtained from participants and from their parents before the baseline measurements. Strict procedures were followed to ensure confidentiality.

\section{MEASURES}

\section{Primary measures}

Body image satisfaction was evaluated at both time points using five questions from the Body and Self-Image Subscale of the Offer Self-Image Questionnaire (OSIQ) (Offer, Ostrov, Howard, \& Dolan, 1992). Even though the OSIQ is designed for the age group of 13-19 years, it was used in this study for consistency purposes, as it has been in other studies (e.g. Dunlop, Burns, \& Bermingham, 2001). In the current study participants were asked how well they agreed with the following five statements: "I'm satisfied when I think about how my body will look in the future", "I usually think I $m$ unattractive and not good looking", "I $m$ satisfied with how my body looks", "I $m$ satisfied with the changes that my body has undergone in the last few years", and "I feel strong and healthy". All items were rated on a four-point Likert scale, where $1=$ Not at all true of me, $2=$ Not true of me, 3 = True of me, and $4=$ Very true of me. Scoring of the second question was reversed, so higher overall scores on this scale reflected higher body image satisfaction. Total scores on this version of the scale ranged from 5 to 20 points. The internal consistency of the body image scores at baseline was Cronbach's $\alpha=.79$ and $\alpha=.80$ at follow-up.

Fitness was assessed in two ways, both objectively and subjectively. Aerobic fitness, the objective measure of fitness, was assessed using the maximal cycle ergometer test on a Monark 839E bike (Monark Exercise $A B$, Vansbro, Sweden). This is an indirect test of maximal oxygen uptake and was developed in Denmark by Hansen, Froberg, Nielsen, and Hyldebrandt (1989). Each participant cycled at a predetermined workload: $40 \mathrm{~W}$ for women and $50 \mathrm{~W}$ for men, which increased by that same amount every three minutes until voluntary exhaustion was reached, or until the pedal rate of $40 \mathrm{rpm}$ could not be maintained. The participants were advised that they could quit the test at any time but were verbally encouraged to give their best efforts and cycle as long as they possibly could. During each test, heart rate was measured with a Polar heart rate monitor (Polar Vantage, Polar Electro, Kempele, Finland). In the last $15 \mathrm{~s}$ of every stage (every time before the workload increased), the participants' ratings of their perceived exertion were obtained on Borg's scale, ranging from $6(7=$ very, very easy) to 20 (19 = very, very hard $)$ (Borg, 1998). Total cycling time was measured in seconds with a stopwatch. Maximal power output per unit of body weight $(\mathrm{W} / \mathrm{kg})$ was calculated for each participant and used as an indicator of cardiorespiratory fitness to compare results. The test was considered maximal if two out of three criteria were met: a) heart rate within $5 \%$ of the age-predicted maximum; b) rating of perceived exertion of at least 19; or c) a researcher's subjective evaluation of exhaustion. This test has been validated, both for adolescents (Arngrimsson, Sveinsson, \& Johannsson, 2008; Eisenmann, 2007) and adults (Eriksen, Tolstrup, Larsen, Grønbæk, \& Helge, 2014).

Self-reported fitness, a subjective measure of fitness, was estimated with the following question, "How good is your aerobic fitness?', with four response options: 1 = bad; 2 = okay; 3 = good; and 4 = excellent. This question was taken from the Health Behaviour in School-aged Children [HBSC] study (Health Behaviour in Schoolaged Children, n.d). The HBSC study has for the last 30 years conducted cross-sectional studies on young people across several European countries, aiming to gain insight into several aspects of young people's psychosocial functioning, health, and well-being.

The participants' PA was assessed using Actigraph activity monitors (Manufacturing Technologies Inc. [MTI], model GT3X), which were carried on the right hip for one week, from the time they woke up until they went to sleep. Presented data are the total time per day, from a weighted average of weekdays and weekend days, spent in moderate-to-vigorous activity (threshold 2000 counts per minute [cpm]; Troiano et al., 2008). A detailed protocol for measurements with accelerometers has been described previously (Magnusson, Sveinsson, Arngrimsson, \& Johannsson, 2008). This particular type of accelerometer gives a reliable and valid measure of PA (Brage, Wedderkopp, Franks, Andersen, \& Froberg, 2003) but is unable to measure all types of activity, e.g. swimming.

\section{Covariates}

Standing height was measured to the nearest $0.1 \mathrm{~cm}$ with a stadiometer (Seca model 217, Seca Ltd., Bir- 
mingham, UK), and body weight was measured on a balance scale (Seca model 813, Seca Ltd., Birmingham, UK) to the nearest $0.1 \mathrm{~kg}$ with participants wearing light clothes. BMI was calculated from participants' weight and height $\left(\mathrm{kg} / \mathrm{m}^{2}\right)$.

Skinfold thickness was measured with a Lange skinfold calliper (Lange, Beta Technology Incorporated, Cambridge, USA) in four places on the left side of the body (subscapular, triceps, biceps, and suprailiac). All skinfold measurements were taken three times, the mean value of the two closest measurements was calculated, and the sum of four skinfolds (mm) was used for analysis. Trained personnel performed all measurements at both time points.

Anxiety and depression were assessed by two subscales of the Symptom Checklist 90 (SCL-90) (Derogatis, Lipman, Rickels, Uhlenhuth, \& Covi, 1974). At both time points, four items were used to measure anxiety and 10 items for depression. They were scored on a five-point Likert-scale rated from 1 (almost never) to 5 (almost always), asking about feelings of anxiety and depression in the preceding week. Total scores on this version of the anxiety scale ranged from 4 to 20 points, and for depression the range was 10 to 50 points. Lower points represent healthier scores on both scales. Examples of questions are "Were you nervous?" for anxiety, and "Did you feel that the future is hopeless?" for depression. Cronbach's $\alpha$ for baseline anxiety and depression were .74 and .89 , respectively. At follow-up, Cronbach's $\alpha$ was .59 and .88, respectively, for these same measures.

\section{STATISTICAL ANALYSES}

Tests of normality and analyses of change of variables across time were calculated using SAS Enterprise Guide, version 4.3 (SAS Institute Inc., Cary, NC), and comparisons between baselines dropouts and non-dropouts were calculated with Microsoft Excel 2010. Study variables were all found to be normally distributed. Descriptive statistics are presented as means and standard deviations. Differences in study variables and covariates from the age groups 15 years and 23 years were analysed with paired t-tests for men and women separately. Any differences in self-reported fitness were assessed with Kendall's Tau-b for the four categories. The $\alpha$ level for significant differences was set at $\leq .05$ in all analyses.

Structural equation modelling (SEM) and factor analyses were conducted with Mplus software version 7.3 (Muthén \& Muthén 1998-2012). SEM was used to evaluate the influence of the primary measures, aerobic fitness, self-reported fitness and PA, at ages 15 and 23 years on body image satisfaction, at the same age, respectively. Covariates in the model consisted of BMI, skinfold thickness, anxiety, and depression for both age groups, and SES for the follow-up group. The model included latent variables for body image satisfaction (five items), depression (10 items), and anxiety (four items). As well as the following observed variables: PA, aerobic fitness, self-reported fitness, BMI, skinfold thickness, and SES. Confirmatory factor analysis was used in the construction of all latent variables, and also to test the fit of the model to the observed data. The relationship between a latent variable and a measured item was expressed as factor loading. Factor analysis on variables measured at baseline revealed factor loadings between 0.52 and 0.78 for the items that manifested body image satisfaction, between 0.48 and 0.87 for the items manifesting depression, and between 0.54 and 0.73 for the items that manifested anxiety. For follow-up measures, the factor loadings for body image satisfaction were $0.52-0.82$, for depression they were 0.38 0.88 , and for anxiety, the factor loadings ranged from 0.11 to 0.76

The recommended (Geiser, 2013) cut-off for fit indices used were Standardised Root Mean Square Residual (SRMR), $0 \leq \mathrm{SRMR} \leq 0.1$; Comparative Fit Index (CFI), $0.95 \leq \mathrm{CFI} \leq 1.00$; and Root Mean Square Error of Approximation (RMSEA), $0 \leq \mathrm{RM}$ $\mathrm{SEA} \leq 0.08$. The structural model consisted of the latent variable of body image satisfaction that was regressed (linear regression) on the observed variables (aerobic fitness, self-reported fitness, and PA) and the above-mentioned covariates. The analyses for the measurement model and the structural model were conducted simultaneously, but separately for gender at each age group. Maximum likelihood was used for parameter estimation. Model fit statistics for the test of measurement invariance of variables across time was calculated in accordance with Little (2013) and can be viewed in Table 2. According to Cheung and Rensvold (2002), if the change in CFI $(\triangle \mathrm{CFI})$ from configural factorial invariance model to weak factorial invariance model is not more than 0.01 , the invariance holds.

\section{RESULTS}

\section{CHANGES IN STUDY VARIABLES}

Descriptive statistics of the variables in the structural model (Figure 1) and covariates are presented in Table 3 .

No difference was found in body image satisfaction scores between baseline and follow-up measurements, within gender. Aerobic fitness was significantly lower at follow-up, both in women $(t(46)$ $=8.9, p<.001)$ and men $(t(58)=10.9, p<.001)$. Fewer women $\left(r_{\tau}=.36, p<.001\right)$ and men $\left(r_{\tau}=.20\right.$, $p=.050)$ perceived their fitness to be good or excellent at age 23 years compared to their assessments at age 15 years (Table 3). Differences in PA between
Body image in adolescence and emerging adulthood 
Table 2

Fit statistic for a test of measurement invariance for body image, depression, anxiety, and self-esteem

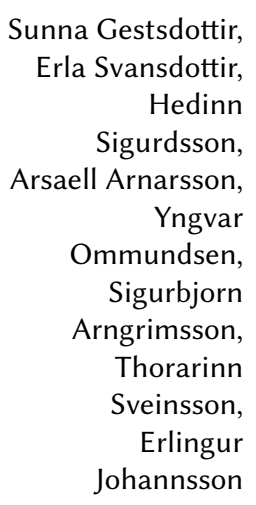

\begin{tabular}{|c|c|c|c|c|c|c|c|}
\hline & $\chi^{2}$ & $d f$ & $p$ & $\mathrm{CFI}$ & $\triangle \mathrm{CFI}$ & RMSEA & SRMR \\
\hline \multicolumn{8}{|l|}{ Women } \\
\hline Model 1 Body image & 36.4 & 28 & .132 & 0.977 & & 0.039 & 0.058 \\
\hline Model 2 Body image & 44.3 & 32 & .070 & 0.967 & 0.010 & 0.044 & 0.096 \\
\hline Model 1 Depression & 249.2 & 157 & .001 & 0.936 & & 0.054 & 0.079 \\
\hline Model 2 Depression & 280.9 & 166 & .001 & 0.921 & 0.015 & 0.060 & 0.101 \\
\hline Model 1 Anxiety & 8.9 & 15 & .881 & 1.000 & & 0.000 & 0.045 \\
\hline Model 2 Anxiety & 44.2 & 18 & .001 & 0.881 & 0.119 & 0.086 & 0.106 \\
\hline Model 1 Self-esteem & 231.5 & 153 & .001 & 0.954 & & 0.051 & 0.072 \\
\hline Model 2 Self-esteem & 240.2 & 162 & .001 & 0.954 & 0 & 0.049 & 0.081 \\
\hline \multicolumn{8}{|l|}{ Men } \\
\hline Model 1 Body image & 47.5 & 29 & .017 & 0.957 & & 0.056 & 0.072 \\
\hline Model 2 Body image & 51.2 & 33 & .023 & 0.958 & 0.001 & 0.052 & 0.085 \\
\hline Model 1 Depression & 231.2 & 151 & .001 & 0.944 & & 0.051 & 0.080 \\
\hline Model 2 Depression & 358.3 & 158 & .001 & 0.887 & 0.057 & 0.071 & 0.108 \\
\hline Model 1 Anxiety & 24.2 & 14 & .040 & 0.958 & & 0.060 & 0.052 \\
\hline Model 2 Anxiety & 40.6 & 17 & .001 & 0.904 & 0.054 & 0.082 & 0.093 \\
\hline Model 1 Self-esteem & 239.1 & 153 & .001 & 0.951 & & 0.053 & 0.067 \\
\hline Model 2 Self-esteem & 260.8 & 162 & .001 & 0.943 & 0.008 & 0.055 & 0.083 \\
\hline
\end{tabular}

Note. Model 1 = Configural model; Model 2 = Weak invariance model; $d f=$ degrees of freedom; RMSEA = Root Mean Square Error of Approximation; CFI = Comparative Fit Index; SRMR = Standardised Root Mean Square Residual; $\Delta \mathrm{CFI}=$ difference between model 1 and model 2.

measurements were quite profound, as it fell by almost half amongst the women $(t(33)=6.6, p<.001)$, or by $6 \%$ per year on average and $60 \%$ for the men $(t(29)=6.1, p<.001)$. Anxiety, depression, and skinfold thickness did not change, but BMI was significantly higher at follow-up among both women $(t(91)=9.2$, $p<.001)$ and men $(t(108)=16.2, p<.001)$.

\section{STRUCTURAL MODEL}

An SEM-based factor analysis was conducted on the latent body image satisfaction construct. The fit of the proposed structural model (Figure 1) to the observed data was tested within the full sample and across gender at both time points (Table 4). Goodness-of-fit indices for the total sample at baseline and follow-up generally gave an acceptable fit: with SRMR being 0.045 for baseline measurements and 0.055 for follow-up; CFI being 0.923 for baseline and 0.911 for follow-up measurements; and RMSEA being 0.081 for baseline and 0.098 for follow-up measurements. The structural model for the total sample accounted for $31 \%$ of the variance in body image satisfaction in adolescence and $26 \%$ of the variance in body image satisfaction in emerging adulthood (Table 4). In the first step of the SEM analysis, body image satisfaction was regressed on the primary measures; in the second step of the SEM, analysis covariates were included in the regression.

\section{FACTORS AFFECTING BODY IMAGE SATISFACTION IN ADOLESCENCE}

Among 15-year-old women (Figure 1), only self-reported fitness was significantly associated with body image satisfaction when body image satisfaction was regressed on the primary variables (objectively and subjectively assessed fitness and PA). When covariates (BMI, skinfold thickness, anxiety, and depression) were added to the model, depression, in addition to self-reported fitness, was associated with body image satisfaction among women. Of the two, self-reported fitness had a stronger relation to body image satisfaction $(\beta=.45, p<.001)$ than depression $(\beta=-.39, p<.001)$. Self-reported fitness and depression explained $46 \%$ of the variance in body image satisfaction. 
Women age 15

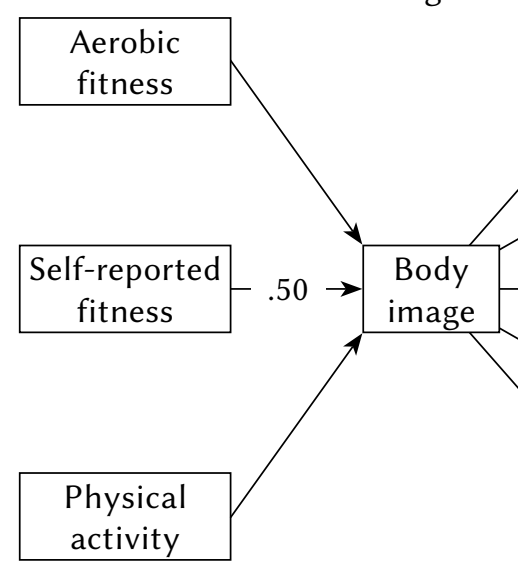

Men age 15

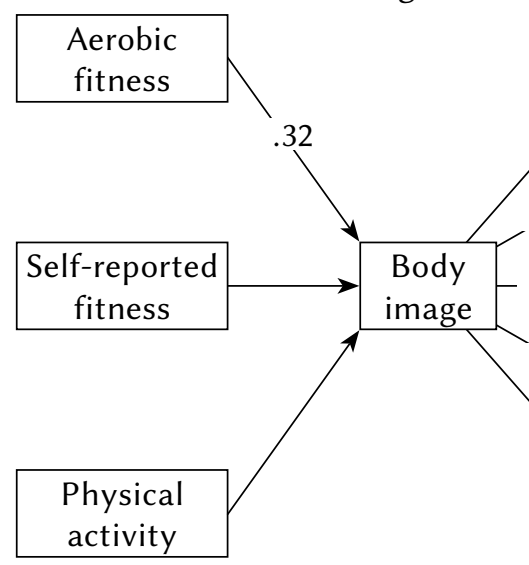

Women age 23

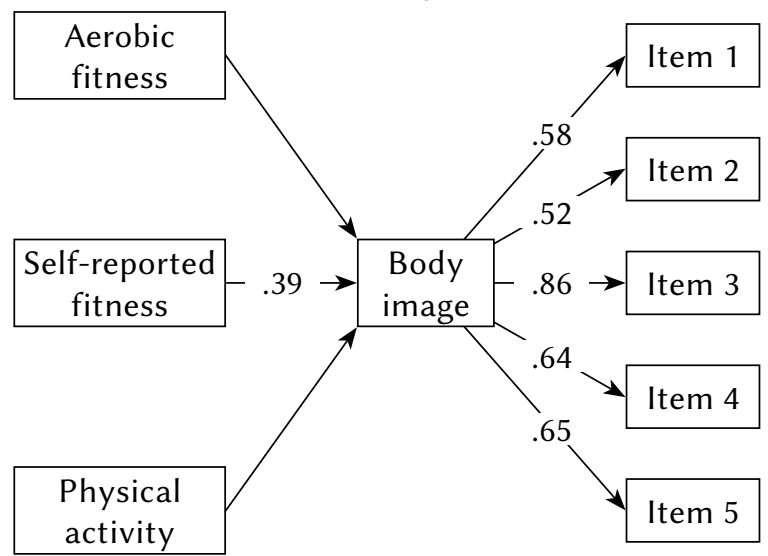

Men age 23

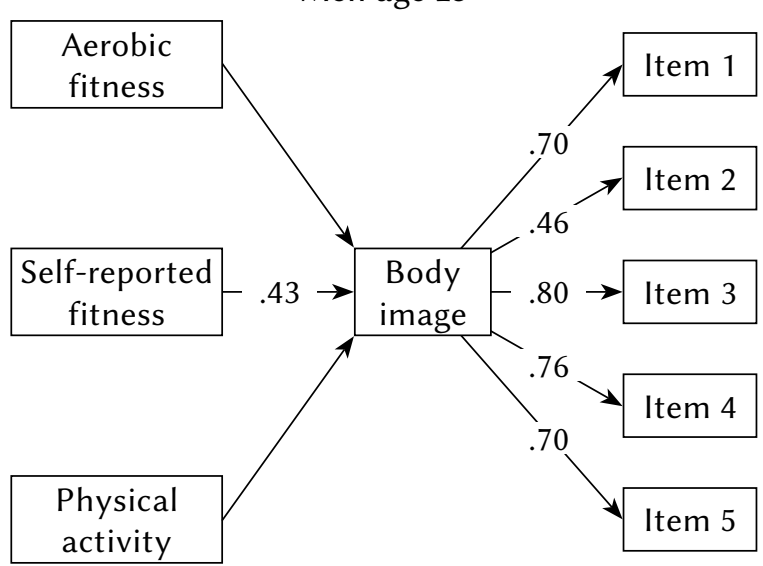

Figure 1. Structural models with statistically significant $(p<.05)$ standardised estimates for primary measures.

Table 3

Participants' characteristics for primary measures and covariates

\begin{tabular}{|c|c|c|c|c|c|c|c|c|}
\hline \multirow{2}{*}{$\begin{array}{l}\text { Gender } \\
\text { Age }\end{array}$} & \multicolumn{3}{|c|}{ Women } & \multicolumn{5}{|c|}{ Men } \\
\hline & 15 & $\min -\max$ & 23 & $\min -\max$ & 15 & $\min -\max$ & 23 & $\min -\max$ \\
\hline Body image & $14.1(2.8)$ & $6.0-20.0$ & $14.8(2.4)$ & $8.0-20.0$ & $15.4(2.7)$ & $5.0-20.0$ & $15.4(2.7)$ & $7.0-20.0$ \\
\hline Aerobic fitness ${ }^{a}$ & $3.1(0.4)$ & $2.0-3.8$ & $2.4(0.5)$ & $1.5-3.6$ & $3.8(0.6)$ & $1.5-4.9$ & $3.0(0.5)$ & $1.7-4.1$ \\
\hline Physical activity ${ }^{b}$ & $51.1(19.7)$ & $12.0-117.7$ & $25.9(15.3)$ & $3.6-70.0$ & $72.4(29.4)$ & $12.7-154.9$ & $28.2(16.8)$ & $1.8-87.9$ \\
\hline \multicolumn{9}{|c|}{ Self-reported fitness } \\
\hline $\operatorname{Bad}(\%)$ & $33(17.8)$ & & $18(20.0)$ & & $19(10.1)$ & & $13(12.0)$ & \\
\hline Okay (\%) & $34(18.4)$ & & $45(48.9)$ & & $36(19.1)$ & & $45(41.7)$ & \\
\hline Good (\%) & $81(43.8)$ & & $29(31.5)$ & & $75(39.7)$ & & $43(39.8)$ & \\
\hline Excellent (\%) & $37(20.0)$ & & 0 & & $59(31.2)$ & & $7(6.5)$ & \\
\hline $\mathrm{BMI}$ & $21.1(2.9)$ & $15.0-31.5$ & $23.5(3.7)$ & $17.7-33.9$ & $21.0(3.0)$ & $16.2-35.8$ & $24.8(4.0)$ & $18.3-40.6$ \\
\hline Sum of skinfold ${ }^{\mathrm{d}}$ & $66.7(22.8)$ & $24.0-148.5$ & $63.9(25.9)$ & $20.0-154.0$ & $46.9(25.5)$ & $17.8-127.0$ & $46.2(21.2)$ & $17.0-117.0$ \\
\hline Anxiety & $7.0(3.0)$ & $4.0-16.0$ & $6.4(2.1)$ & $4.0-13.0$ & $5.7(2.3)$ & $4.0-20.0$ & $5.5(2.0)$ & $4.0-13.0$ \\
\hline Depression & $17.3(6.9)$ & $10.0-43.0$ & $16.1(6.1)$ & $10.0-39.0$ & $14.5(5.8)$ & $10.0-50.0$ & $14.7(5.2)$ & $10.0-39.0$ \\
\hline
\end{tabular}

Note. Data is presented as mean $( \pm \mathrm{SD})$, range, and count $(\%)$.

${ }^{a}$ Measured in W/kg; ${ }^{b}$ Presented as total minutes in moderate-vigorous activity; ${ }^{\mathrm{B} M I}=$ Body $\operatorname{mass}$ index $\left(\mathrm{kg} / \mathrm{m}^{2}\right)$; ${ }^{\mathrm{d}} \mathrm{Sum}$ of four skinfolds (triceps, bicep, subscapular, suprailiac) measured in $\mathrm{mm}$. 
Table 4

Fit statistic for proposed structural model of primary measures

\begin{tabular}{lcccccc}
\hline .10 & $\begin{array}{c}\text { Total sample } \\
\text { age } 15\end{array}$ & $\begin{array}{c}\text { Women } \\
\text { age } 15\end{array}$ & $\begin{array}{c}\text { Men } \\
\text { age } 15\end{array}$ & $\begin{array}{c}\text { Total sample } \\
\text { age 23 }\end{array}$ & $\begin{array}{c}\text { Women } \\
\text { age 23 }\end{array}$ & $\begin{array}{c}\text { Men } \\
\text { age 23 }\end{array}$ \\
\hline RMSEA & .08 & .10 & .07 & .10 & .11 & .09 \\
CFI & .92 & .90 & .93 & .91 & .88 & .09 \\
SRMR & .05 & .05 & .05 & .06 & .07 & .06 \\
$\mathrm{R}^{2}$ & .31 & .35 & .17 & .26 & .31 & .22 \\
\hline
\end{tabular}

Sunna Gestsdottir,

Erla Svansdottir,

Hedinn

Sigurdsson,

Arsaell Arnarsson,

Yngvar

Ommundsen,

Sigurbjorn

Arngrimsson,

Thorarinn

Sveinsson,

Erlingur

Johannsson

Note. RMSEA = Root Mean Square Error of Approximation; CFI = Comparative Fit Index; SRMR = Standardised Root Mean Square Residual.

Among 15-year-old men (Figure 1), aerobic fitness was the only variable having a significant association with body image satisfaction when body image satisfaction was regressed on primary variables. After adding the covariates to the model, skinfold thickness, and aerobic fitness had a significant relation to men's body image satisfaction. The association was stronger for skinfold thickness $(\beta=-.33, p<.001)$ compared with aerobic fitness $(\beta=.30, p=.004)$. These two variables accounted for $26 \%$ of the variance in the body image satisfaction of men.

\section{FACTORS AFFECTING BODY IMAGE SATISFACTION IN EMERGING ADULTHOOD}

Among 23-year-old women, self-reported fitness stood out as the only significant variable when regressing body image satisfaction on primary variables (Figure 1). When covariates (BMI, skinfold thickness, depression, anxiety, and SES) were added to the model, BMI, depression and self-reported fitness were shown to have a significant relation to body image satisfaction, with BMI having the strongest association $(\beta=-.45, p<.001)$. Self-reported fitness had the second strongest association with body image satisfaction $(\beta=.37, p<.001)$, followed by depression $(\beta=-.20, p=.027)$. Together the three variables explain $49 \%$ of the variance in women's body image satisfaction at age 23 years.

Among 23-year-old men, self-reported fitness had the only significant association with body image satisfaction when it was regressed on the primary measures (Figure 1). When covariates were added to the model the following four variables: skinfold thickness, BMI, depression, and self-reported fitness had a significant relation to men's body image satisfaction. Skinfold thickness had the strongest relation to body image satisfaction $(\beta=-.46, p=.002)$, with others being depression $(\beta=-.37, p<.001)$, BMI $(\beta=.34, p=.016)$, and self-reported fitness $(\beta=.32$, $p<.001)$. Together the four variables accounted for $42 \%$ of the variance in men's body image satisfaction at age 23 years.

\section{DISCUSSION}

Regarding the primary measures, an association was found between fitness and body image satisfaction, but no association was found between body image satisfaction and PA. This was shown to be the case, both among men and women and in both age groups. In light of previous studies showing the impact of PA on individuals' health and well-being (Penedo \& Dahn, 2005), our results are somewhat surprising, but there may be several explanations for these contradictory findings. Firstly, there is scant research on the association between PA and body image satisfaction. Secondly, many studies revealing a positive effect of PA on mental well-being have relied on self-reports, but in the current study PA was assessed with accelerometers, which provide more accurate and detailed measures of PA than a self-report. Thirdly, our finding could be attributed to a lack of power, as only $43-47 \%$ of adolescent women and men, and $72-75 \%$ of emerging adults, carried the accelerometer on their hips during the whole measurement period (one week). Fourthly, the association between PA and body image satisfaction can be very complex, as studies (Prichard \& Tiggemann, 2008; Tiggemann \& Williamson, 2000) have found that the motivation for being physically active or the cognitive beliefs regarding exercise have a stronger impact on peoples' bodily sensations rather than the frequency of exercise. Hence, it could be that people are drawn out of personal motives to specific physical activities that elicit specific sensory experiences and feeling states that are not readily captured when measuring PA by means of objective, accelerometer-based tools. Fifthly, nowadays young individuals (as well as adults) spend a lot of time on computers, smartphones or smart devices, doing work, school work, playing games, communicating, or using social networking sites (SNS), which have led to a more sedentary behaviour than before. It could be speculated that even though an individual exercises regularly and has a healthy state of fitness, he or she also may have a lot of sedentary behaviour due to the above-mentioned reasons. If that same person wears an acceler- 
ometer to measure PA, it would probably show a lot more sedentary behaviour than PA, which could be one reason why PA has no association with body image in the current study, whereas the use of SNS increases dissatisfaction with one's body, as studies have indicated it does (Sampasa-Kanyinga, Chaput, \& Hamilton, 2016; Tiggemann \& Slater, 2013).

Regarding changes in variables from baseline to follow-up, we found no evidence of changes in body image satisfaction, depression, anxiety, or skinfold thickness between the ages of 15 and 23 years, although both fitness and PA decreased and BMI increased during the study period. The decline found in PA mirrors the results found in other studies that measured PA objectively (Corder et al., 2015) and subjectively (Dumith, Gigante, Domingues, \& Kohl, 2011). The reduction in aerobic fitness found in the current study, which presumably is due to declining PA over the study period, is in agreement with previous findings (Tomkinson \& Olds, 2007). The decrease in participants' aerobic fitness paralleled their self-evaluation of fitness. For many years, researchers have focused on body image dissatisfaction in women (Martin-Ginis, Strong, Arent, Bray, \& Bassett-Gunter, 2014; Stice \& Whitenton, 2002), but as Sladek, Engeln, and Miller (2014) have pointed out, the issue in relation to men has largely been ignored. The likely reason is that men usually have a better body image than women (Frost \& McKelvie 2004), which was also found in the current study sample (Gestsdottir et al., 2015).

\section{FACTORS ASSOCIATED WITH WOMEN'S BODY IMAGE SATISFACTION}

In the current study, women's body image satisfaction, at both time-points, was related most strongly to how they perceived their fitness followed by depression, whereas no association was found with aerobic fitness, PA, and body composition. In terms of body composition, one explanation might be that body image satisfaction, and self-perceptions of physical fitness are both psychological conceptualisations; thus, they share more common conceptual variance in a hierarchical conceptualisation of the self (Fox, 1998) than does body image with an endogenous influence like actual body size and shape (Davis, 1997). Nevertheless, in emerging adulthood, body shape and size seem to be important to women as well as their self-perceptions. Apparently, in this age period, objective measures of body size and shape take on increased perceived importance in self-evaluations of body image as part of the physical self for women (Fox, 1998). BMI, which had the strongest association with body image satisfaction in emerging adulthood, was negatively related to body image satisfaction, while self-reported fitness and depression were pos- itively and negatively associated with body image satisfaction, respectively. It was noteworthy to find that depression had a significant relation to women's body image satisfaction at both time points, perhaps hinting that when dealing with emotional problems among women (women are most commonly treated for depression and anxiety [Kessler, 2003]) a focus should be on increasing their body image satisfaction.

The fact that only subject factors associate with body image satisfaction in adolescent women in the current study might be due to the physical changes in their bodies after puberty, but study results (e.g. O’Dea \& Abraham, 1999) indicate that young women are likely to be unsatisfied with their appearance following puberty even though their physical shape is healthy. Therefore, enhancement of their self-perceived fitness may seem a viable approach to obtain better body image satisfaction. The societal standards of appearance explained earlier could be another component explaining why only subjective factors related to body image satisfaction in adolescent women. Wilson, Tripp, and Boland (2005) reported that women are more likely to internalise societal standards of attractiveness that partially mediate the effect of subjective perceptions of body weight on body image. They also pointed out that the subjectivity in women's perceptions of body weight is likely to be a key factor in causing more body image dissatisfaction (Wilson et al., 2005). The same comparison to the "ideal" body presented in the media seems to be an ongoing process in emerging adulthood, but it could be speculated that with becoming more mature in emerging adulthood women also rely on their physical health, i.e. body composition, and therefore there is a mixture of both subjective and objective factors associating with body image satisfaction. In the current study, the variance in body image satisfaction explained by variables associated with body image satisfaction increased from $46 \%$ in adolescence to $49 \%$ in emerging adulthood, which is less than the increase across age among men.

\section{FACTORS ASSOCIATED WITH MEN'S BODY IMAGE SATISFACTION}

Regarding aerobic fitness, it was interesting to find that it was only associated with body image satisfaction among adolescent men. As skinfold thickness and aerobic fitness were the only two variables significantly associated with body image satisfaction among adolescent men, it can be speculated that their ability and activity in sports are highly important and enhance their muscular, masculine, sociocultural body ideal, which has been found to be important to men (e.g. Jones \& Crawford, 2005). Increasing their aerobic physical capability may, therefore, prove effective for increasing their body image satisfaction.
Body image in adolescence and emerging adulthood 
Sunna Gestsdottir,

Erla Svansdottir,

Hedinn

Sigurdsson,

Arsaell Arnarsson,

Yngvar

Ommundsen, Sigurbjorn

Arngrimsson,

Thorarinn

Sveinsson,

Erlingur

Johannsson
Among emerging adult men, skinfold thickness still had the strongest association with body image satisfaction, but aerobic fitness did not. However, more subjective factors, including depression and self-reported fitness, associated with men's body image satisfaction in their emerging adulthood. This is somewhat in line with results indicating that higher levels of muscle dissatisfaction among men are related to more depressive symptoms (e.g. Olivardia, Pope Jr, Borowiecki III, \& Cohane, 2004). These findings indicate differences that may reflect differentiated attempts to generate a strategy for promoting a positive body image or protecting the self (Crocker \& Park, 2003), the latter of which, within limits, can be regarded as positive and self-enhancing. It could also be speculated that the similarity in factors across genders, which were found to associate with body image satisfaction in the current study, could be explained by the SNS that are not only targeting young women with images of slim, attractive, blemish-free females but also they are targeting men in their emerging adulthood with images of lean, muscular, and strong men. Interestingly, the variance in body image satisfaction explained by variables associated with body image satisfaction increased more in men than in women, from $26 \%$ in adolescence to $42 \%$ eight years later. This large increase is probably due to the change of factors affecting body image satisfaction, with more self-perception affecting body image satisfaction in emerging adulthood.

\section{STRENGTH AND LIMITATION}

The main strength of the current study is the design, which allowed tracking of the same individuals over two-time points in their life. Moreover, we measured PA objectively, and also provided measures of both self-reported fitness and objective measures of aerobic fitness, which has not been conducted before, to our knowledge. By using SEM analysis, we were able to account for the measurement error of latent variables in the analysis. By spanning the transitional period between adolescence and emerging adulthood, a clearer understanding of the trajectories of body image satisfaction during the period and how it is associated with fitness and PA has been added to the literature. A weakness of the study is the low number of participants who had a valid PA measurement, which may have limited the power of the study. Another weakness is that we did not have a measure of SES for the baseline measures. However, SES measured at the follow-up did not have any association with body image satisfaction.

In future studies, it would be interesting to compare the effects of variables other than fitness, which can be measured both subjectively and objectively, such as PA and BMI, upon body image satisfaction.
Results of such comparisons could indicate that both objective and subjective measures of variables are needed to explain the variance in body image. It would also be interesting to study how SNS associates with body image satisfaction in young people at different life stages. Finally, an interesting analysis would be to see if self-esteem mediates the association between fitness or PA and body image satisfaction.

\section{CONCLUSIONS}

Body image satisfaction is different across genders, and so are factors associated with body image, both across gender and age. Among adolescent women, only subjective measures associated with their body image satisfaction, whereas only objective measures associated with body image satisfaction among men of the same age. In emerging adulthood, factors associated with body image satisfaction were a mixture of objective and subjective factors among both men and women. Results from the current study show that the sources needed to account for the variance in body image satisfaction, which is a powerful, influential factor on mental well-being in adolescence and emerging adulthood, includes a combination of both objective and subjective indices. This study indicates that men and women need different approaches when it comes to efforts to improve their body image satisfaction and thereby their mental well-being in this age span.

\section{RefERENCES}

Arngrimsson, S. A., Sveinsson, T., \& Johannsson, E. (2008). Peak oxygen uptake in children: Evaluation of an older prediction method and development of a new one. Pediatric Exercise Science, 20, 62-73.

Bearman, S. K., Presnell, K., Martinez, E., \& Stice, E. (2006). The skinny on body dissatisfaction: A longitudinal study of adolescents girls and boys. Journal of Youth and Adolescence, 35, 229-241. doi: 10.1007/s10964-005-9010-9

Borg, G. (1998). Perceived exertion and pain scales. Champaign: Human Kinetics.

Brage, S., Wedderkopp, N., Franks, P. W., Andersen, L. B., \& Froberg, K. (2003). Reexamination of validity and reliability of the CSA monitor in walking and running. Medicine and Science in Sports and Exercise, 35, 1447-1454. doi: 10.1249/01. Mss.0000079078.62035.Ec

Bucchianeri, M. M., Arikian, A. J., Hannan, P. J., Eisenberg, M. E., \& Neumark-Sztainer, D. (2013). Body dissatisfaction from adolescence to young adulthood: Findings from a 10-year longitudinal study. Body Image, 10, 1-7. doi: 10.1016/j.bodyim.2012.09.001 
Böhm, A., \& Heitmann, B. L. (2013). The use of bioelectrical impedance analysis for body composition in epidemiological studies. European Journal of Clinical Nutrition, 67, 79-85. doi: http://dx.doi. org/10.1038/ejcn.2012.168

Cafri, G., \& Thompson, J. K. (2004). Measuring male body image: A review of the current methodology. Psychology of Men and Masculinity, 5, 18-29. doi: 10.1037/1524-9220.5.1.18

Cheung, G. W., \& Rensvold, R. B. (2002). Evaluating goodness-of-fit indexes for testing measurement invariance. Structural Equation Modeling, 9, 233255. doi: 10.1207/S15328007sem0902_5

Corder, K., Sharp, S. J., Atkin, A. J., Griffin, S. J., Jones, A. P., Ekelund, U., \& van Sluijs, E. M. F. (2015). Change in objectively measured physical activity during the transition to adolescence. British Journal of Sports Medicine, 49, 730-736. doi: 10.1136/ bjsports-2013-093190

Crocker, J., \& Park, L. E. (2003). Seeking self-esteem: Construction, maintenance, and protection of self-worth. In M. Leary \& J. Tangney (eds.), Handbook of self and identity (pp. 291-313). New York: Guilford Press.

Cruz-Saez, S., Pascual, A., Salaberria, K., \& Echeburua, E. (2015). Normal-weight and overweight female adolescents with and without extreme weight-control behaviours: Emotional distress and body image concerns. Journal of Health Psychology, 20, 730-740. doi: 10.1177/1359105315580214

Darby, A., Hay, P., Mond, J., Rodgers, B., \& Owen, C. (2007). Disordered eating behaviours and cognitions in young women with obesity: Relationship with psychological status. International Journal of Obesity, 31, 876-882. doi: 10.1038/ sj.ijo.0803501

Davis, C. (1997). Body image, exercise, and eating behaviors. In K. R. Fox (ed.), The physical self: From motivation to well-being (pp. 143-174). Champaign, IL: Human Kinetics.

Derogatis, L. R., Lipman, R. S., Rickels, K., Uhlenhuth, E. H., \& Covi, L. (1974). The Hopkins Symptom Checklist (HSCL). A measure of primary symptom dimensions. Modern Problems of Pharmacopsychiatry, 7, 79-110.

Dooley, B., Fitzgerald, A., \& Giollabhui, N. (2015). The risk and protective factors associated with depression and anxiety in a national sample of Irish adolescents. Irish Journal of Psychological Medicine, 32, 93-105. doi: 10.1017/ipm.2014.83

Dumith, S. C., Gigante, D. P., Domingues, M. R., \& Kohl, H. W. (2011). Physical activity change during adolescence: A systematic review and a pooled analysis. International Journal of Epidemiology, 40, 685-698.

Dunlop, R., Burns, A., \& Bermingham, S. (2001). Parent-child relations and adolescent self-image following divorce: A 10 year study. Journal of Youth and Adolescence, 30, 117-134. doi: 10.1023/A:1010389923248
Eisenmann, J. C. (2007). Aerobic fitness, fatness and the metabolic syndrome in children and adolescents. Acta Paediatrica, 96, 1723-1729. doi: 10.1111/j.1651-2227.2007.00534.x

Eriksen, L., Tolstrup, J. S., Larsen, S., Grønbæk, M., \& Helge, J. (2014). A maximal cycle test with good validity and high repeatability in adults of all ages. International Journal of Sports Medicine, 35, 1184-1189. doi: 10.1055/s-0034-1376973

Fox, K. R. (1998). Advances in the measurement of the physical self. In J. L. Duda (ed.), Advances in sport and exercise psychology measurement (pp. 295-310). Morgantown, WV: Fitness Information Technology.

Frost, J., \& McKelvie, S. (2004). Self-esteem and body satisfaction in male and female elementary school, high school, and university students. Sex Roles, 51, 45-54. doi: 10.1023/B:Sers.0000032308.90104.C6

Gaspar, M. J. M., Amaral, T. F., Oliveira, B. M. P. M., \& Borges, N. (2011). Protective effect of physical activity on dissatisfaction with body image in children - A cross-sectional study. Psychology of Sport and Exercise, 12, 563-569. doi: 10.1016/j. psychsport.2011.05.004

Geiser, C. (2013). Data analysis with Mplus. New York: The Guilford Press.

Gestsdottir, S., Arnarsson, A., Magnusson, K., Arngrimsson, S. A., Sveinsson, T., \& Johannsson, E. (2015). Gender differences in development of mental well-being from adolescence to young adulthood: An eight-year follow-up study. Scandinavian Journal of Public Health, 43, 269-275. doi: 10.1177/1403494815569864

Gestsdottir, S., Svansdottir, E., Ommundsen, Y., Arnarsson, A. Arngrimsson, S., Sveinsson, T., \& Johannsson, E. (2016). Do aerobic fitness and self-reported fitness in adolescence differently predict body image in young adulthood? An eight year follow-up study. Mental Health and Physical Activity, 10, 40-47. doi: 10.1016/j.mhpa.2015.12.001

Hansen, H. S., Froberg, K., Nielsen, J. R., \& Hyldebrandt, N. (1989). A new approach to assessing maximal aerobic power in children: The Odense School Child Study. European Journal of Applied Physiology and Occupational Physiology, 58, 618624. doi: 10.1007/Bf00418508

Haugen, T., Säfvenbom, R., \& Ommundsen, Y. (2011). Physical activity and global self-worth: The role of physical self-esteem indices and gender. Mental Health and Physical Activity, 4, 49-56. doi: http:// dx.doi.org/10.1016/j.mhpa.2011.07.001

Hausenblas, H. A., \& Fallon, E. A. (2006). Exercise and body image: A meta-analysis. Psychology and Health, 21, 33-47. doi: 10.1080/14768320500105270

Health Behaviour in School-aged Children. (n.d.). International coordination centre, child and health research unit. Retrieved from http://www.hbsc.org/ [accessed November 10, 2016].
Body image in adolescence and emerging adulthood 
Sunna Gestsdottir,

Erla Svansdottir,

Hedinn

Sigurdsson,

Arsaell Arnarsson, Yngvar

Ommundsen, Sigurbjorn

Arngrimsson,

Thorarinn

Sveinsson,

Erlingur

Johannsson
Holsen, I., Jones, D. C., \& Birkeland, M. B. (2012) Body image satisfaction among Norwegian adolescents and young adults: A longitudinal study of the influence of interpersonal relationships and BMI. Body image, 9, 201-208. doi: 10.1016/j.bodyim.2012.01.006

Jones, D. C., \& Crawford, J. K. (2005). Adolescent boys and body image: Weight and muscularity concerns as dual pathways to body dissatisfaction. Journal of Youth and Adolescence, 34, 629-636. doi: 10.1007/s10964-005-8951-3

Kessler, R. C. (2003). Epidemiology of women and depression. Journal of Affective Disorders, 74, 5-13. doi: 10.1016/S0165-0327(02)00426-3

Lawler, M., \& Nixon, E. (2011). Body dissatisfaction among adolescent boys and girls: The effects of body Mass, peer appearance culture and internalization of appearance ideals. Journal of Youth and Adolescence, 40, 59-71. doi: 10.1007/s10964-0099500-2

Levine, M. P., \& Chapman, K. (2012). Media influences on body image. In T. F. Cash \& L. Smolak (eds.), Body image: A handbook of science, practice, and prevention ( $2^{\text {nd }}$ ed.) (pp. 101-109). New York: Guilford.

Little, T. D. (2013). Longitudinal structural equation modeling. New York: Guilford Press.

Magnusson, K. T., Sveinsson, T., Arngrimsson, S. A., \& Johannsson, E. (2008). Predictors of fatness and physical fitness in nine-year-old Icelandic school children. International Journal of Pediatric Obesity, 3, 217-225. doi: 10.1080/17477160802169482

Markey, C. N. (2010). Invited commentary: Why body image is important to adolescent development. Journal of Youth and Adolescence, 39, 1387-1391. doi: 10.1007/s10964010-9510-0

Martin Ginis, K., Strong, H. A., Arent, S. M., Bray, S. R., \& Bassett-Gunter, R. L. (2014). The effects of aerobic-versus strength-training on body image among young women with pre-existing body image concerns. Body Image, 11, 219-227. doi: 10.1016/j.bodyim.2014.02.004

McCabe, M. P., \& Ricciardelli, L. A. (2003). Sociocultural influences on body image and body changes among adolescent body and girls. Journal of Social Psychology, 143, 5-26. doi: 10.1080/00224540309598428

Meland, E., Haugland, S., \& Breidablik, H. J. (2007). Body image and perceived health in adolescence. Health Education Research, 22, 342-350. doi: 10.1093/Her/Cyl085

Mellor, D., Fuller-Tyszkiewicz, M., McCabe, M. P., \& Ricciardelli, L. A. (2010). Body image and self-esteem across age and gender: A short-term longitudinal study. Sex Roles, 63, 672-681. doi: 10.1007/ s11199-010-9813-3

Muthén, L. K., \& Muthén, B. O. (1998-2012). Mplus user's guide ( $7^{\text {th }}$ ed.). Los Angeles, CA: Muthén and Muthén.
O’Dea, J. A., \& Abraham, S. (1999). Onset of disordered eating attitudes and behaviors in early adolescence: Interplay of pubertal status, gender, weight, and age. Adolescence, 34, 671-679.

Offer, D., Ostrov, E., Howard, K. J., \& Dolan, S. (1992). Offer Self-Image Questionnaire. Revised. Los Angeles: Western Psychological Services.

Olivardia, R., Pope Jr, H. G., Borowiecki III, J. J., \& Cohane, G. H. (2004). Biceps and body image: The relationship between muscularity and self-esteem, depression, and eating disorder symptoms. Psychology of Men and Masculinity, 5, 112-120. doi: 10.1037/1524-9220.5.2.112

Ortega, F. B., Ruiz, J. R., Castillo, M. J., \& Sjostrom, M. (2008). Physical fitness in childhood and adolescence: A powerful marker of health. International Journal of Obesity, 32, 1-11. doi: 10.1038/ sj.ijo.0803774

Penedo, F. J., \& Dahn, J. R. (2005). Exercise and well-being: A review of mental and physical health benefits associated with physical activity. Current Opinion in Psychiatry, 18, 189-193.

Prichard, I., \& Tiggemann, M. (2008). Relations among exercise type, self-objectification, and body image in the fitness centre environment: The role of reasons for exercise. Psychology of Sport and Exercise, 9, 855-866. doi: http://dx.doi.org/ 10.1016/j.psychsport.2007.10.005

Rosenberg, M., Schooler, C., Schoenbach, C., \& Rosenberg, F. (1995). Global self-esteem and specific self-esteem - Different concepts, different outcomes. American Sociological Review, 60, 141-156. doi: 10.2307/2096350

Sampasa-Kanyinga, H., Chaput, J. P., \& Hamilton, H. (2016). Use of social networking sites and perception and intentions regarding body weight among adolescents. Obesity Science and Practice, 2, 32-39. doi: 10.1002/osp4.26

Sarwer, D. B., Thompson, J. K., \& Cash, T. F. (2005). Body image and obesity in adulthood. Psychiatric Clinics of North America, 28, 69-87, viii. doi: 10.1016/j.psc.2004.09.002

Sladek, M. R., Engeln, R., \& Miller, S. A. (2014). Development and validation of the Male Body Talk Scale: A psychometric investigation. Body Image, 11, 233-244. doi: 10.1016/j.bodyim.2014.02.005

Sopanaru, C. Bojian, A., \& Lorga, M. (2016). Gender differences regarding body image, stress and coping strategies in adolescence. Archives of Medical Science - Civilization Disease, 1, e36-e42. doi: 10.5114/amscd.2016.59897

Smolak, L. (2004). Body image in children and adolescents: Where do we go from here? Body image, 1, 15-28. doi: 10.1016/S1740-1445(03)00008-1

Statistics Iceland. (n.d.-a). Population: Statistics. Retrieved from http://www.statice.is/Statistics/ Population/Citizenship-and-country-of-birth [accessed May 16, 2014]. 
Statistics Iceland. (n.d.-b). Religion: Statistics. Retrieved from http://www.statice.is/Statistics/Population/Religious-organizations [accessed May 16, 2014].

Stice, E. (2002). Risk and maintenance factors for eating pathology: A meta-analytic review. Psychological Bulletin, 128, 825-848. doi: 10.1037//00332909.128.5.825

Stice, E., \& Whitenton, K. (2002). Risk factors for body dissatisfaction in adolescent girls: A longitudinal investigation. Developmental Psychology, 38, 669-678. doi: 10.1037//0012-1649.38.5.669

Tiggemann, M., \& Slater, A. (2013). NetGirls: The Internet, Facebook, and body image concern in adolescent girls. International Journal of Eating Disorders, 46, 630-633. doi: 10.1002/eat.22141

Tiggemann, M., \& Williamson, S. (2000). The effect of exercise on body satisfaction and self-Esteem as a function of gender and age. Sex Roles, 43, 119127. doi: $10.1023 / \mathrm{a}: 1007095830095$

Tomkinson, G. R., \& Olds, T. S. (2007). Secular changes in pediatric aerobic fitness test performance: The global picture. Medicine and Sport Science, 50, 46-66. doi: 10.1159/0000101075

Troiano, R. P., Berrigan, D., Dodd, K. W., Masse, L. C., Tilert, T., \& Mcdowell, M. (2008). Physical activity in the United States measured by accelerometer. Medicine and Science in Sports and Exercise, 40, 181-188. doi: 10.1249/mss.0b013e31815a51b3

Vygotsky, L. S. (1978). Mind in society. The development of higher psychological processes. Massachusetts: Harvard University Press.

Wiederman, M. W., \& Pryor, T. L. (2000). Body dissatisfaction, bulimia, and depression among women: The mediating role of drive for thinness. International Journal of Eating Disorders, 27, 90-95. doi: 10.1002/(Sici)1098-108x(200001)27:1<90::AidEat $10>3.0 . \mathrm{Co} ; 2-0$

Wilson, J. M. B., Tripp, D. A., \& Boland, F. J. (2005). The relative contributions of subjective and objective measures of body shape and size to body image and disordered eating in women. Body Image, 2, 233-247. doi: 10.1016/j.bodyim.2005.06.001 